\title{
Perceptions of engagement in health care among patients with tuberculosis: a qualitative study
}

This article was published in the following Dove Medical Press journal:

Patient Preference and Adherence

\author{
Jing Ren' \\ Quanlei $\mathrm{Li}^{2}$ \\ Tianhua Zhang ${ }^{3}$ \\ Xiaomei $\mathrm{Li}^{4}$ \\ Shaoru Zhang ${ }^{1,4}$ \\ Jiaojiao Wright ${ }^{2}$ \\ Haini Liu ${ }^{4}$ \\ Zhongqiu $\mathrm{Hua}^{4}$ \\ 'School of Public Health, Health \\ Science Center, Xi'an Jiaotong \\ University, Xi'an, Shanxi, China; \\ ${ }^{2}$ School of Nursing, Johns Hopkins \\ University, Baltimore, MD, USA; \\ ${ }^{3}$ Shaanxi Provincial Institute for \\ Tuberculosis Control and Prevention, \\ Xi'an, Shanxi, China; ${ }^{4}$ School of \\ Nursing, Health Science Center, Xi' \\ an Jiaotong University, Xi'an, Shanxi, \\ China
}

Correspondence: Shaoru Zhang Health Science Center, Xi'an Jiaotong University, No 76 Yanta West Rd, Yanta, Xi'an, Shanxi 71006I, China

Tel +860298265 7015

Fax +860298265 7017

Email tgshru0II@I26.com
Purpose: Adherence to treatment is cited as a key challenge in fighting tuberculosis (TB). Treatment of TB requires patients to actively engage in their care. The purpose of this study was to explore the perceptions of patients with TB regarding their engagement in health care.

Patients and methods: The study was conducted in three medical wards in one hospital. Purposive sampling was used to recruit participants. Semi-structured, audiotaped interviews were conducted and analyzed using thematic analysis.

Results: Twenty-three patients participated in the study. Four major themes emerged: 1) devaluing engagement; 2) interacting with health care providers (HCPs); 3) facing inability; and 4) seeking external support.

Conclusion: The patients' perceptions of their engagement in health care were generally negative. Paying attention to the preferences and needs of patients and making decisions accordingly are effective strategies for promoting patient engagement. Moreover, HCPs should be aware of their crucial role in helping patients make sense of what engagement is and how to engage. In the process of engagement, providers should establish effective interactions with patients and cooperate with family and peers.

Keywords: tuberculosis, patient engagement, qualitative study, treatment adherence

\section{Introduction}

Tuberculosis (TB) is a chronic infectious disease that threatens public health. There were an estimated 10.0 million new cases of TB globally in 2017, ${ }^{1}$ and China ranked second among 30 countries with a high TB burden. ${ }^{1,2}$ TB treatment is a long-term, complex, and challenging process. Patients need to take a combination of drugs in short-course chemotherapy lasting for at least 6 months. ${ }^{3}$ Meanwhile, they also need to make numerous behavioral changes in areas such as diet, daily activity, and lifestyle. ${ }^{4}$ Thus, being cured is largely in the hands of the patients and depends on patients effectively engaging in self-care activities. ${ }^{5}$ At present, adherence to treatment is cited as a key challenge in fighting TB. ${ }^{3,6,7}$ Poor adherence puts patients at high risk of experiencing prolonged infection, relapse, and drug resistance, ${ }^{8}$ and these outcomes make treatment more difficult and more complex. Globally, 3.6\% of new cases and $17 \%$ of previously treated cases had multidrug-resistant TB ${ }^{1}$ Over the years, although various adherence interventions have been implemented, ${ }^{3,6}$ the incidence of serious consequences has remained high. ${ }^{1}$ In response, the first pillar of the Stop TB Strategy promoted by the WHO is "integrated, patient-centered TB care and prevention". 5 This pillar emphasizes the importance of the patient's crucial role in promoting adherence and achieving positive health outcomes, ${ }^{7}$ and it is therefore necessary to promote TB patient engagement (PE) in their own health care. ${ }^{9}$ 
PE, which is grounded in the principles of patient-centered care ${ }^{10}$ aims to give the leading role back to patients and allow them to become effective and skilled self-managers of their own health. ${ }^{10-12} \mathrm{PE}$ originated in Western countries, ${ }^{12}$ and there is currently no universally accepted definition of PE. The most recent concept analysis of PE defines it as "a desire and capability to actively choose to participate in care in a way uniquely appropriate to the individual, in cooperation with a health care provider (HCP) or institution, for the purposes of maximizing outcomes or improving experiences of care". ${ }^{13}$ This definition emphasizes the crucial role of patients and the importance of their willingness to engage. Increased evidence has demonstrated that more engaged patients enjoy higher treatment adherence, better health outcomes, and better care experiences ${ }^{14}$ compared with those who are less engaged in their care. Scholars in PE have also discovered that the preference for engagement differs according to the cultural environment. ${ }^{15}$ The engagement of patients in the management of their own health is well established in most Western countries, ${ }^{16}$ while research on PE in China is still in its infancy. ${ }^{17}$ Furthermore, there has been a surge in publications about factors associated with PE, but those studies have largely involved patients with noninfectious diseases. ${ }^{10,16,18,19}$ To the best of our knowledge, there is little information about PE in health care for infectious diseases. ${ }^{20}$ Although previous studies have provided clues on how to engage patients, these results cannot be directly extended without further examination of patients' perceptions in a specific context. ${ }^{21}$ To promote engagement in practice, a deep understanding of TB patients' perceptions of engagement in China is required.

Therefore, the purpose of the current study is to investigate perceptions of engagement in health care from the perspective of patients with TB in China and how these may be influenced by other factors. We hope that these results can provide useful information for designing appropriate interventions to promote TB patients' engagement in health care.

\section{Methods}

\section{Design}

This was a qualitative study utilizing semi-structured interviews to collect data. The Consolidated Criteria for Reporting Qualitative Research ${ }^{22}$ were applied to ensure study rigor (see Table S1).

\section{Setting}

This study was carried out in three wards in a 1,000-bed TB specialized tertiary hospital in Xi'an, China, that supports patients from a wide and diverse geographic area. Considering the participants' health status and availability, the interviews were conducted in a comfortable consulting room within the hospital that offered privacy and adequate ventilation (to minimize transmission).

\section{Participants}

Through communications with nurse unit managers, purposive sampling was used to recruit participants who differed in characteristics. The inclusion criteria were as follows: the participants must be at least 18 years, diagnosed with TB and could speak and understand Chinese (mandarin). Participants with HIV/AIDS or other serious mental illnesses or with assessed cognitive, visual, or hearing impairments were excluded.

\section{Data collection}

Data were collected via open-ended, semi-structured interviews from October 2017 to January 2018. The original interview guide was developed based on a literature review and group discussion. We conducted two pilot interviews, reflected on the process, and revised the interview guide (see Table 1). Probing questions were used as needed to elicit more information during the interviews (eg, "Why do you think that?").

All the interviews were conducted face-to-face in Chinese (mandarin) by the first author. Before each interview, the researcher explained the content and purpose of the interview to the participants in detail. The researcher clarified that he/she worked separately from the clinical HCPs and welcomed frank discussions of every aspect of the patients' care. All the interviews were audiotaped (range: 30-65 minutes, mean: 45 minutes). Memos were written throughout the data collection and analysis phases to capture nonverbal information and reflections while refining the sampling strategy. ${ }^{23}$ Sampling was continued until no new information emerged and data saturation was achieved. ${ }^{24}$ At the end of the interviews, each participant completed a sociodemographic sheet.

Table I Interview guide

\begin{tabular}{l}
\hline I. Can you describe what PE in health care means to you? \\
2. Can you describe your experience engaging in health care? \\
\hline 3. What things facilitate or hinder your engagement in your own \\
health care? \\
4. Are there any individuals or groups that are important when you \\
engage in health care? \\
\hline $\begin{array}{l}\text { 5. Is there anything else about engagement that you want to talk to } \\
\text { me about? }\end{array}$ \\
\hline
\end{tabular}

Abbreviation: PE, patient engagement. 


\section{Data analysis}

Data analysis started as soon as the first interview was completed. All audiotapes were transcribed verbatim (using anonymous participant identifiers). QRS NVivo 11.0 software was used to manage the transcripts. We performed the analysis according to the six steps of thematic analysis. ${ }^{25}$ Themes were progressively presented based on codes. Three researchers analyzed the transcripts independently, and differences in coding and themes were discussed in team discussions until consensus was reached. All quotes, codes, and themes in Chinese were identified and translated into English. Two bilingual experts checked the consistency and accuracy between the Chinese and English languages. Participants' demographics were analyzed using descriptive statistics.

\section{Ethical considerations}

The Ethics Committee from Xi'an Jiaotong University approved the study (reference: 2017-518). All participants were fully informed about the content of study. The voluntary and confidential nature of the study was stressed, and the participants had the right to withdraw from study at any time. In addition, the fact that refusal or withdrawal from the study would not influence the care the patients received was also emphasized. Verbal and written informed consent were obtained prior to the interviews. Finally, a $\$ 5$ gift was given to each patient as a token of appreciation for his/her time. This study was carried out in accordance with the Declaration of Helsinki.

\section{Results}

Twenty-five participants were invited, and 23 agreed to participate in the interview (see Table 2). Two patients declined verbally and did not provide reasons for their decision. The results illustrate how participants with TB perceived engagement in their own health care. Four themes were identified from the data analysis (see Figure 1), including devaluing engagement, interacting with HCPs, facing inability, and seeking external support. Several subthemes were also discovered and illustrated with quotes (see Table 3 ).

\section{Theme I: Devaluing engagement}

This theme reflects the patients' negative attitudes toward engaging in health care. Our findings indicate that most of the patients viewed engagement as "useless" and "meaningless" and believed that their condition would not change regardless of whether they engaged in their own health care. Moreover, the patients also pointed out a variety of predicted negative outcomes of engagement, including anxiety about treatment,
Table 2 Demographics of the participants $(n=23)$

\begin{tabular}{|l|l|}
\hline Variables & N (\%) or (mean \pm SD) \\
\hline Gender & $\mathrm{I}$ I (47.82) \\
\hline Male & $12(52.18)$ \\
\hline Female & $30.27(9.05)$ \\
\hline Age (mean \pm SD) & $7(30.43)$ \\
\hline Employment & $9(39.14)$ \\
\hline Employed & $7(30.43)$ \\
\hline Not employed & $5(21.74)$ \\
\hline Others (student/retired/farmer) & $11(47.83)$ \\
\hline Education level & $7(30.43)$ \\
\hline Primary school or less & $10(43.48)$ \\
\hline Middle school & $13(56.52)$ \\
\hline College or above &
\end{tabular}

physical burden, and greater pressure. Seventeen of the 23 patients expressed directly that they were reluctant to engage in their own health care. While three of the remaining patients did not respond directly, they expressed their perspective by shaking their head or hand when asked to provide more details. Although the last three patients showed a desire to engage in their care, they also admitted that they were unsure about how to engage and what the consequences of engagement could be.

\section{Theme 2: Interacting with HCPs}

This theme illustrates that the patients' relationship with HCPs impacted their willingness to engage. These interactions were embodied in two aspects: 1) trust and dependence and 2) passive obedience.

\section{Trust and dependence}

When talking about health management, the majority of the participants said that it was the HCPs' duty because they had expert knowledge and power. Moreover, the participants repeatedly stressed that their role was to be a "patient" and "unprofessional". Thus, all the participants held ideas about how to behave as a patient and had a concordant sense about engaging in health care: "To engage in health care is to follow doctors' orders, as well as take medication, have injections and receive treatment as scheduled" (P17).

\section{Passive obedience}

In the interviews, many patients realized the importance of communication and indicated that they felt actively engaged 


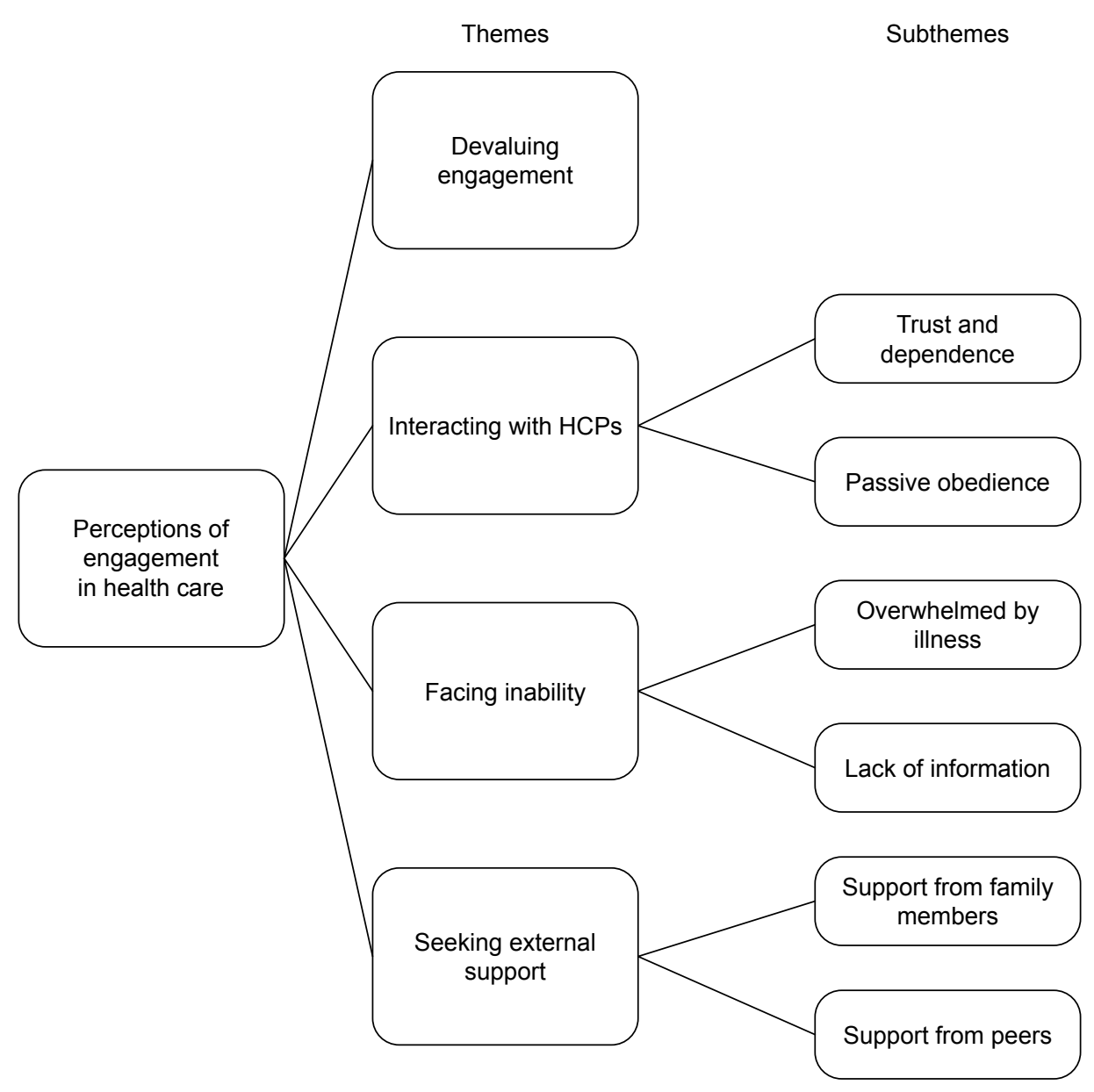

Figure I Patient's perceptions of engagement in health care. Abbreviation: HCPs, health care providers.

only when HCPs communicated with them directly. However, the patients complained that the paternalistic approach of HCPs drove them to behave passively. For instance, the majority of patients said that they had no opportunities to talk with their HCPs and that the HCPs decided what patients needed to know. Other patients who attempted to ask questions felt that their HCPs were not willing to discuss and address their problems and concerns. Therefore, the patients perceived that they had no right to engage and described themselves as "laboratory mice". The patients felt a strong sense of powerlessness and disappointment, which annoyed them.

\section{Theme 3: Facing inability}

This theme illustrates how personal characteristics influence PE. This theme was divided into two further subthemes: overwhelmed by illness and lack of information.

\section{Overwhelmed by illness}

In the interviews, the patients felt that the side effects of treatment were worse than the symptoms of TB. Chest pain, respiratory difficulties, fatigue, and loss of appetite were the most frequently mentioned side effects. Moreover, many participants said they suffered a life-changing reduction in their ability to carry out many activities of daily living, such as climbing stairs and toileting. "Tired" and "weakness" were the words used most frequently by patients to describe their condition. All of these challenges caused the patients to feel that they were unable to engage. As one patient said, "Maybe I would be involved if I felt better" (P12). In addition to physical burden, the patients also stated that they suffered high psychological pressure. Concerns about the uncertainty of illness, long-term hospitalization, high financial expense, family commitments, and missed work opportunities were common among the patients and caused considerable distress.

\section{Lack of information}

A large number of the patients lacked knowledge about TB and its symptoms and treatment, and they showed a strong willingness to gain information at the beginning of their hospitalization. The patients tended to seek information from 
Table 3 Illustrative quotes for the themes and subthemes

\begin{tabular}{|c|c|}
\hline \multicolumn{2}{|c|}{ Theme I: Devaluing engagement } \\
\hline \multirow[t]{6}{*}{ Subthemes } & Quotes \\
\hline & "There is no difference in engaging or not. I still get shots and take medications every day" (PI3). \\
\hline & "It is useless because l'm sick now, and it can't change anything, and I don't want to add extra stress on myself" (PI5). \\
\hline & $\begin{array}{l}\text { "It will probably make me more worried about my condition after engaging in health care }(\ldots) \text { and might be even } \\
\text { worse" (P23). }\end{array}$ \\
\hline & "For me, knowing more brings more stress" (P5). \\
\hline & "Yes, of course I need to engage because it's all about me. But there is not much that I can do" (P8). \\
\hline \multicolumn{2}{|c|}{ Theme 2: Interacting with HCPs } \\
\hline \multirow[t]{3}{*}{ Trust and dependence } & "It is the doctors' job. We don't need to do that" (PI4). \\
\hline & "Doctors have the best understanding of my health condition. I trust the doctors overall. (...) We are the patients" (P20). \\
\hline & $\begin{array}{l}\text { "I have never thought about that because health care providers are the professionals, and we only need to follow their } \\
\text { commands" (P2). }\end{array}$ \\
\hline \multirow[t]{4}{*}{ Passive obedience } & $\begin{array}{l}\text { "Since admission, I have no choice but to totally obey the doctors, and they also never talk with you about anything. } \\
\text { Only when the results are abnormal will they come and tell me what to do. Otherwise, they will not come and talk to } \\
\text { me" (PI6). }\end{array}$ \\
\hline & "After hospitalization, I lost control. (...) We are pushed around like laboratory mice" (PI8). \\
\hline & $\begin{array}{l}\text { "Doctors control everything when you are hospitalized. We have no control over things like medication, examinations. } \\
\text { We have to follow their orders" (PI4). }\end{array}$ \\
\hline & $\begin{array}{l}\text { "It doesn't make any sense. They will not talk with you. One time, I asked a nurse a question, but she refused to tell me } \\
\text { and told me to ask the doctors. It is hard to contact the doctors. So forget about that, just follow them" (PI9). }\end{array}$ \\
\hline \multicolumn{2}{|c|}{ Theme 3: Facing inability } \\
\hline \multirow{6}{*}{$\begin{array}{l}\text { Overwhelmed by } \\
\text { illness }\end{array}$} & "Taking these medications makes me tired. I don't want to do anything but have a good rest” (P5). \\
\hline & $\begin{array}{l}\text { "I lost my appetite recently. That medicine upsets my stomach, which makes me weak and lethargic. (...) It is hard to } \\
\text { spare extra effort to consider other things" (PI2). }\end{array}$ \\
\hline & "I cannot lie on my side because of excess fluid. My breathing is short, and my chest is painful. It torments me" (P2). \\
\hline & "I think TB is an obstinate disease, it drains my energy" (PI6). \\
\hline & "I cannot do anything since I came here. I cannot help with family; I cannot work" (PI9). \\
\hline & $\begin{array}{l}\text { "So far, we have spent tens of thousands, that is too much. I have been thinking of quitting treatment if it continues to } \\
\text { cost so much" (P9). }\end{array}$ \\
\hline \multirow[t]{4}{*}{ Lack of information } & $\begin{array}{l}\text { "We are blind as a bat. We have no idea about the progress of treatment and the results of examinations. So we hope } \\
\text { the doctors can at least tell us what is going on. Sometimes I feel like something is wrong. It is not what we tell doctors } \\
\text { but what doctors tell us. It seems our roles are reversed" (PI6). }\end{array}$ \\
\hline & $\begin{array}{l}\text { "It is terrible to get information online; I feel so upset because it said TB is like cancer. Some website even said that TB } \\
\text { can't be cured and may get worse in the future" (P7). }\end{array}$ \\
\hline & $\begin{array}{l}\text { "Since hospitalization, I have had lots of examinations. I sometimes wonder why I need to have each examination, but } \\
\text { nobody answers me" (PI9). }\end{array}$ \\
\hline & me by on ward rounds, I can talk to my doctor but only for a few minutes. They are always busy" (P4). \\
\hline
\end{tabular}

\section{Theme 4: Seeking external support}

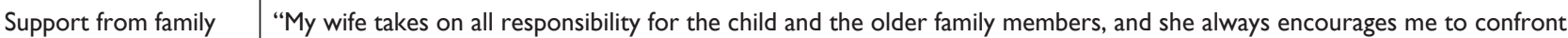
members the future with optimism" (PI).

"I need to engage in treatment for my family. I want to recover as soon as possible so that they will not worry about me and I can go home earlier" (P9).

"My family asks around to help me. I can depend on them, they take care of my daily life and are concerned about my treatment" (PI8).

"My parents give me a hand paying for treatment. They want me to be cured quickly" (PI5).

"I don't want my parents to come here. This place is special because all the patients are infected. I am worried that they will get infected too" (PII). 
Table 3 (Continued)

\begin{tabular}{|l|l|}
\hline Theme 4: Seeking external support \\
\hline Subthemes & Quotes \\
\hline Support from peers & $\begin{array}{l}\text { "Once a time, I had some spicy food and milk. My roommate reminded me that I could not eat these during drug therapy. } \\
\text { I found that to be helpful" (P2). }\end{array}$ \\
\cline { 2 - 2 } & $\begin{array}{l}\text { "When I have some emotional problems, I always choose to talk to my roommates. They always listen to and inspire me. } \\
\text { I believe this is very important because I realized that we are in the same boat. I am not alone. This makes me feel much } \\
\text { better" (P7). }\end{array}$ \\
\cline { 2 - 3 } & "I don't want to talk with others. But we are the same here, (...) cross-infectious" (PI4). \\
\cline { 2 - 3 } & "Maybe it is useful, but I am not sure about the accuracy of what they are talking about. So (...)" (PI0). \\
\hline
\end{tabular}

Abbreviations: HCPs, health care providers; P, patient; TB, tuberculosis.

the Internet, but they often obtained little information and were left with a sense of uncertainty and anxiety. The patients also relied on their HCPs to provide valuable information and appreciated the chance to talk with their HCPs, especially during ward rounds. However, the HCPs were not fully present to talk with patients or focus on patients' concerns because of time constraints. This situation exacerbated the patients' feelings of uncertainty and helplessness, which inhibited them from asking their HCPs for information. When asked about the content of communication with HCPs, the patients expressed a wish to know the progress of treatment and the results of laboratory tests even if they could not fully understand the information.

\section{Theme 4: Seeking external support}

This theme focuses on the importance and impact of external support on PE in health care. The theme includes two aspects: family members and peers.

\section{Support from family members}

Many patients acknowledged the significant role of family members in supporting their engagement. During the patients' hospitalization, family members provided powerful support for the patients both emotionally and financially. Family members could also support patients to engage with their care by acting as bedside monitors by keeping track of medication and talking with HCPs. For patients who were accompanied by family members, the value of the support they received was evident. However, most of the patients reported distancing themselves from their family members due to a fear of transmitting the disease to others. In fact, many patients stayed in the hospital alone and took care of themselves on their own.

\section{Support from peers}

The patients expressed how important it was to have peers with whom they could interact. For instance, 19 patients said that peers helped them adopt healthy behaviors and habits by sharing personal experiences and giving necessary reminders, especially when their family members were unavailable. Meanwhile, some patients had experienced social isolation after being diagnosed with TB, and their peers became their social partners during hospitalization. Peers helped the patients to alleviate pressure by listening when they were in bad mood and building positive attitudes toward treatment and life in the future. However, a minority reported that they avoided speaking with other patients for various reasons, such as protecting them from cross infection and questioning the accuracy of information obtained from their peers.

\section{Discussion}

To the best of our knowledge, this is the first study that offers novel insights into TB patients' perceptions of engagement in their own health care in China. The findings show that the participants held negative attitudes toward engagement and felt restricted by their interactions with HCPs and their own abilities when attempting to engage. Meanwhile, the participants attempted to seek support from others.

The first finding in this study indicates that patients with TB held a negative attitude toward engagement. The patients were more concerned about the disadvantages of engagement in health care, which were predominately psychological and physical pressure. In this context, the patients emphasized that engagement in health care is "useless" and expressed a negative attitude. This result is similar to a cross-sectional study in Hong Kong in which the patients believed PE to be important and beneficial but not completely necessary. ${ }^{17}$ The literature suggests that this finding might be related to patients' self-abasement or inability to express their needs. ${ }^{17}$ Although a minority of the patients in this study showed a desire to engage, they also tended to express a passive attitude due to a lack of clarity regarding engagement activities. ${ }^{26}$ Although there is evidence that engagement conveys more benefits, ${ }^{27}$ patients will actively engage only when they 
realize the benefits of engagement in health care. ${ }^{28}$ Based on a concept analysis of $\mathrm{PE}$, engagement in health care requires collaboration between HCPs and patients. ${ }^{13}$ In particular, HCPs should lead and foster patients to acquire awareness of and confidence in engaging effectively in the care process. ${ }^{10}$ These findings highlight the crucial role that HCPs play in the success of PE.

While patients in the present study fully trusted and relied on HCPs and considered HCPs to be professional figures possessing expert knowledge, the patients strongly believed their own most important activity was treatment compliance. Many studies have confirmed that this finding might be related to the ideology of traditional medicine, in which the role of the patient is subordinate to that of HCPs organizationally, emotional, and intellectually. ${ }^{29}$ In the present study, though the patients were reluctant to engage actively, they still wanted to communicate with their HCPs to obtain necessary information. That information provided them with an opportunity to learn about and understand their condition $^{30}$ and empowered them to contribute as active partners. ${ }^{31,32}$ Earlier studies have found that acquiring basic information from HCPs is a prerequisite for PE. ${ }^{33}$ However, due to time constraints and heavy workloads, HCPs were not fully present to talk with the patients in this study or focus on their concerns. ${ }^{17,34}$ Although we advocate for hospitals to adopt patient-centered missions, the medical process is doctor-centered in most cases. ${ }^{35}$ Sometimes, HCPs directly decided what the patients needed to know, resulting in the patients feeling as if their own health care was out of their control. Similarly, other researchers have also found that HCP's authoritarian behaviors - whether intentionally or unintentionally - are linked to patient passivity toward engagement. ${ }^{17}$ All of the above issues heighten patient uncertainty about their health condition and strengthen their feelings of inability and dependence during hospitalization.

In our study, health condition also had an impact on the patients' willingness and ability to engage. Inpatients with TB suffer from a serious condition and frequently must undergo a course of chemotherapy for a period of time. Fatigue might be the most common distressing symptom for these patients. In addition, many patients report serious adverse reactions, and increases in disease symptoms are the main barriers to engagement. As previous studies have confirmed that experiencing a deterioration in health condition may alter patients' desire and ability to engage, ${ }^{36,37}$ those who are in good health are likely to have a higher willingness to become engaged. Meanwhile, patients receiving treatment for TB often suffer excessive psychological burdens and express a need to discuss their emotional reactions. ${ }^{38}$ However, these needs are typically ignored during clinical treatment. ${ }^{34}$ Currently, studies on individual-related factors affecting PE mainly refer to demographic characteristics, ${ }^{39}$ such as level of education, age, and level of income, while analyses of the psychological factors involved in PE remain limited. ${ }^{10}$ A recent study highlighted that particular attention needs to be paid to supporting patients in the process of psychological adaptation to their illness, which may prevent them from being an active partner. ${ }^{11}$ Perhaps because of these extreme conditions, Bickmore called the experience of being hospitalized "one of the most disempowering situations one can experience in modern society". ${ }^{40}$ Physical and psychological distress create a tremendous sense of powerlessness among patients, which leads them to doubt their ability to engage. Therefore, it is important to identify personalized ways of engaging patients when engagement is appropriate and does not constitute an unwanted burden for them. ${ }^{10}$

Moreover, our findings provide novel insights into the role of family members and peers in PE. Consistent with previous studies, ${ }^{37}$ the interviewed participants emphasized that family members' support was their motivation to persist in treatment. The functions of family members included providing care for daily life and financial support. Similarly, other researchers have reported that family members perform different roles in the hospital environment to promote $\mathrm{PE}$ in care, such as patient advocate, educator, and health manager. Family members are sometimes seen as a conduit between the patient and HCPs. ${ }^{41}$ Furthermore, the role of family involvement as a crucial component of promoting PE has been shown in many studies. ${ }^{42}$ However, although patients in this study valued family support, fear of infecting others frequently undermined the patients' willingness to be accompanied by their family members while in the hospital. To some extent, fear of infection reduced opportunities for family involvement, which resulted in a lower level of PE. Meanwhile, peer support was often mentioned by the patients as an important supplement to family support. Patients with TB typically encounter social isolation during hospitalization because of the need to protect their privacy and prevent emotional stress. ${ }^{43}$ In the hospital, talking with peers met the patients' need for social interaction and helped to alleviate their psychological burden. Similarly, Croft et al reported that support provided by peers extends to helping patients accept their diagnosis and build confidence in treatment. ${ }^{44}$ To some extent, peers promoted $\mathrm{PE}$ by giving reminders and providing basic care and necessary information, particularly when family members were not present. Similarly, peer support 
has been reported to be an effective approach for promoting health and behavioral changes ${ }^{45}$ However, several patients were reluctant to interact more with their peers, and this was related to their specific surroundings and uncertainty about the accuracy of information provided by peers. These findings suggest that taking advantage of the peer role in the delivery of clinical TB services may be conducive to PE. Studies on the relationship between peer support and engagement will thus be needed in the future.

\section{Limitations}

There are some limitations that must be acknowledged. First, the participants were recruited from one hospital, which might impose some inherent selection bias. During the process, we used the purposive sampling strategy to obtain participants with maximum variation until data saturation. Second, given that perceptions of engagement may differ among outpatients with TB, future studies should broaden the sampling scope. Third, power relationships might influence open discourse among patients. Before the interviews, we tried to encourage the patients to relax and provided them with more opportunities to express their thoughts, and clinical HCPs were not present during the interviews. Fourth, this study mainly focused on exploring patients' perceptions of engagement, although the findings can be used as a reference for future interventions. However, whether patients' willingness and actual behavior are consistent need to be assessed via more empirical studies using mixed methods in the future.

\section{Conclusion}

The findings describe TB patients' perceptions of engagement in their own health care. The patients expressed a low preference for engaging in their own health care, mainly due to perceived negative outcomes. The findings demonstrate the need to explore approaches that cultivate patients' awareness of engagement, as this may be crucial in promoting PE. Additionally, HCPs should be aware of their pivotal role in the process and tailor interventions according to the needs and health conditions of their patients. Meanwhile, the roles of family members and peers should be utilized to a reasonable extent to support patients' engagement in their care.

\section{Data sharing statement}

The data will not be shared in order to protect the participants' anonymity.

\section{Acknowledgments}

The authors are grateful to the 23 patients for sharing their hospitalized experiences and providing their valuable opinions.
The authors also thank the hospital settings authorities for their powerful support. This research was supported by National Science Foundation of China (grant number: 71774131). The fund supported to complete the study design, data collection and interpretation, writing, and translation of the manuscript.

\section{Author contributions}

JR, SRZ, and XML planned and designed the study. The study was supervised by SRZ. JR and THZ contributed to the data collection. All authors contributed to the data analysis and the drafting and revising of the paper gave final approval of the revision to be published, and agree to be accountable for all aspects of the work.

\section{Disclosure}

The authors report no conflicts of interest in this work.

\section{References}

1. World Health Organization (WHO). Global Tuberculosis Report 2018. Geneva, Switzerland: World Health Organization.

2. Wu S, Wang H, Li B. Tuberculosis controlling, from China's perspective. J Infect Public Health. 2018;11(2):300.

3. Wurie FB, Cooper V, Horne R, Hayward AC. Determinants of nonadherence to treatment for tuberculosis in high-income and middleincome settings: a systematic review protocol. BMJ Open. 2018;8(1): e019287.

4. Egwaga S, Range N, Lwilla F, et al. Assessment of patient preference in allocation and observation of anti-tuberculosis medication in three districts in Tanzania. Patient Prefer Adherence. 2008;2(3):1-6.

5. Odone A, Roberts B, Dara M, van den Boom M, Kluge H, Mckee M. People- and patient-centred care for tuberculosis: models of care for tuberculosis. Int J Tuberc Lung Dis. 2018;22(2):133-138.

6. Valencia S, León M, Losada I, Sequera VG, Fernández Quevedo M, García-Basteiro AL. How do we measure adherence to anti-tuberculosis treatment? Expert Rev Anti Infect Ther. 2017;15(2):157-165.

7. Tola HH, Karimi M, Yekaninejad MS. Effects of sociodemographic characteristics and patients' health beliefs on tuberculosis treatment adherence in Ethiopia: a structural equation modelling approach. Infect Dis Poverty. 2017;6(1):167-176.

8. Sagwa EL, Ruswa N, Mavhunga F, Rennie T, Leufkens HG, MantelTeeuwisse AK. Adverse events and patients' perceived health-related quality of life at the end of multidrug-resistant tuberculosis treatment in Namibia. Patient Prefer Adherence. 2016;10:2369-2377.

9. Chavan D. Fighting TB requires empowered patients. BMJ. 2017; 356:i6344.

10. Barello S, Graffigna G, Vegni E, Savarese M, Lombardi F, Bosio AC. 'Engage me in taking care of my heart': a grounded theory study on patient-cardiologist relationship in the hospital management of heart failure. BMJ Open. 2015;5(3):e005582.

11. Graffigna G, Barello $S$. The value of measuring patient engagement in healthcare: new frontiers for healthcare quality. In: Graffigna G, editor. Promoting Patient Engagement and Participation for Effective Healthcare Reform. Hershey, PA: IGI Global; 2016:192-214.

12. Barello S, Graffigna G, Vegni E. Patient engagement as an emerging challenge for healthcare services: mapping the literature. Nurs Res Pract. 2012;2012(2):1-7.

13. Higgins T, Larson E, Schnall R. Unraveling the meaning of patient engagement: a concept analysis. Patient Educ Couns. 2017;100(1): $30-36$. 
14. Hibbard JH, Greene J. What the evidence shows about patient activation: better health outcomes and care experiences; fewer data on costs. Health Aff. 2013;32(2):207-214.

15. Osborn R, Squires D. International perspectives on patient engagement: results from the 2011 Common wealth Fund Survey. J Ambul Care Manage. 2012;35(2):118-128.

16. Graffigna G, Barello S, Libreri C, Bosio CA. How to engage type-2 diabetic patients in their own health management: implications for clinical practice. BMC Public Health. 2014;14(1):648.

17. Wong ELY, Lui S, Cheung AWL, et al. Views and experience on patient engagement in healthcare professionals and patients - how are they different? Open J Nurs. 2017;07(06):615-629.

18. Gruman J, Rovner MH, French ME, et al. From patient education to patient engagement: implications for the field of patient education. Patient Educ Couns. 2010;78(3):350-356.

19. Rodriguez KM. Intrinsic and extrinsic factors affecting patient engagement in diabetes self-management: perspectives of a certified diabetes educator. Clin Ther. 2013;35(2):170-178.

20. Rajabiun S, Mallinson RK, Mccoy K, et al. "Getting Me Back on Track": The role of outreach interventions in engaging and retaining people living with HIV/AIDS in medical care. AIDS patient care and STDs. 2007;21(s1):S-20-S-29.

21. Karazivan P, Dumez V, Flora L, et al. The patient-as-partner approach in health care: a conceptual framework for a necessary transition. Acad Med. 2015;90(4):437-441.

22. Tong A, Sainsbury P, Craig J. Consolidated criteria for reporting qualitative research (COREQ): a 32-item checklist for interviews and focus groups. Int J Qual Health Care. 2007;19(6):349-357.

23. Birks M, Chapman Y, Francis K. Memoing in qualitative research probing data and process. J Res Nurs. 2008;13(1):68-75.

24. O'Reilly M, Parker N. 'Unsatisfactory Saturation': a critical exploration of the notion of saturated sample sizes in qualitative research. Qual Res. 2013;13(2):190-197.

25. Braun V, Clarke V. Using thematic analysis in psychology. Qual Res Psychol. 2006;3(2):77-101.

26. Tobiano G, Marshall A, Bucknall T, Chaboyer W. Patient participation in nursing care on medical wards: an integrative review. Int J Nurs Stud. 2015;52(6):1107-1120.

27. Greene J, Hibbard JH, Sacks R, Overton V. When seeing the same physician, highly activated patients have better care experiences than less activated patients. Health Aff. 2013;32(7):1299-1305.

28. Hwu YJ, Yu CC. Exploring health behavior determinants for people with chronic illness using the constructs of planned behavior theory. J Nurs Res. 2006;14(4):261-270.

29. Aasen EM, Kvangarsnes M, Heggen K. Perceptions of patient participation amongst elderly patients with end-stage renal disease in a dialysis unit. Scand J Caring Sci. 2012;26(1):61-69.

30. Brumwell A, Noyes E, Kulkarni S, Lin V, Becerra MC, Yuen CM. A rapid review of treatment literacy materials for tuberculosis patients. Int J Tuberc Lung Dis. 2018;22(3):336-341.
31. Eldh AC, Luhr K, Ehnfors M. The development and initial validation of a clinical tool for patients' preferences on patient participation - the 4Ps. Health Expect. 2015;18(6):2522-2535.

32. Eldh AC, Ekman I, Ehnfors M. Conditions for patient participation and non-participation in health care. Nurs Ethics. 2006;13(5):503-514.

33. Tobiano G, Bucknall T, Marshall A, Guinane J, Chaboyer W. Patients' perceptions of participation in nursing care on medical wards. Scand J Caring Sci. 2016;30(2):260-270.

34. Ting X, Yong B, Yin L, Mi T. Patient perception and the barriers to practicing patient-centered communication: a survey and in-depth interview of Chinese patients and physicians. Patient Educ Couns. 2016;99(3):364-369.

35. Cao J, Wei J. Evolution of the perception of the doctor's role in China. Lancet. 2014;384(9945):742.

36. Larsson IE, Sahlsten MJ, Segesten K, Plos KA. Patients' perceptions of barriers for participation in nursing care. Scand J Caring Sci. 2011; 25(3):575-582.

37. Manias E. Communication relating to family members' involvement and understandings about patients' medication management in hospital. Health Expect. 2015;18(5):850-866.

38. Marra CA, Marra F, Colley L, Moadebi S, Elwood RK, Fitzgerald JM. Health-related quality of life trajectories among adults with tuberculosis: differences between latent and active infection. Chest. 2008;133(2): 396-403.

39. Graffigna G, Barello S. Spotlight on the Patient Health Engagement model (PHE model): a psychosocial theory to understand people's meaningful engagement in their own health care. Patient Prefer Adherence. 2018;12:1261-1271.

40. Bickmore TW, Pfeifer LM, Jack BW. Taking the time to care: empowering low health literacy hospital patients with virtual nurse agents. In: Proceedings of the 27th international conference on Human factors in computing systems; April 04-09, 2009; Boston, USA. New York: ACM.

41. Mishra SR, Haldar S, Pollack AH, et al. "Not Just a Receiver": understanding patient behavior in the hospital environment. In: Proceedings of 2016 CHI Conference on Human Factors in Computing Systems; May 07-12, 2016; San Jose, USA. New York: ACM. 2016.

42. Carman KL, Dardess P, Maurer M, et al. Patient and family engagement: a framework for understanding the elements and developing interventions and policies. Health Aff. 2013;32(2):223-231.

43. Yin X, Yan S, Tong Y, et al. Status of tuberculosis-related stigma and associated factors: a cross-sectional study in central China. Trop Med Int Health. 2018;23(2):199-205.

44. Croft LA, Hayward AC, Story A. Tuberculosis peer educators: personal experiences of working with socially excluded communities in London. Int J Tuberc Lung Dis. 2013;17(10 Suppl 1):36-40.

45. Ramchand R, Ahluwalia SC, Xenakis L, Apaydin E, Raaen L, Grimm G. A systematic review of peer-supported interventions for health promotion and disease prevention. Prev Med. 2017;101:156-170. 


\section{Supplementary material}

Table SI COREQ checklist

\begin{tabular}{|c|c|c|}
\hline No item & Guide questions/description & Reported on page number \\
\hline \multicolumn{3}{|l|}{ Domain I: Research team and reflexivity } \\
\hline \multicolumn{3}{|l|}{ Personal characteristics } \\
\hline I. Interviewer/facilitator & Which author/s conducted the interview or focus group? & Page 5, Data collection, by lead author \\
\hline 2. Credentials & What were the researcher's credentials? eg, PhD, MD & MSN, PhD \\
\hline 3. Occupation & What was their occupation at the time of the study? & Full-time PhD student \\
\hline 4. Gender & Was the researcher male or female? & Not reported in paper, female \\
\hline 5. Experience and training & What experience or training did the researcher have? & $\begin{array}{l}\text { Not reported in paper, participating in } \\
\text { qualitative research seminars }\end{array}$ \\
\hline \multicolumn{3}{|l|}{ Relationship with participants } \\
\hline 6. Relationship established & $\begin{array}{l}\text { Was a relationship established prior to study } \\
\text { commencement? }\end{array}$ & $\begin{array}{l}\text { Not reported in paper, cooperate with } \\
\text { three chief nurses }\end{array}$ \\
\hline $\begin{array}{l}\text { 7. Participant knowledge of the } \\
\text { interviewer }\end{array}$ & $\begin{array}{l}\text { What did the participants know about the researcher? eg, } \\
\text { personal goals, reasons for doing the research }\end{array}$ & $\begin{array}{l}\text { Page 5, Data collection, fully informed } \\
\text { the purpose and content of study }\end{array}$ \\
\hline 8. Interviewer characteristics & $\begin{array}{l}\text { What characteristics were reported about the } \\
\text { interviewer/facilitator? eg, Bias, assumptions, reasons, and } \\
\text { interests in the research topic }\end{array}$ & $\begin{array}{l}\text { Not reported in paper, the lead author } \\
\text { is a PhD and would like to introduce } \\
\text { patient engagement into health care } \\
\text { field especially to Chinese health } \\
\text { care field }\end{array}$ \\
\hline \multicolumn{3}{|l|}{ Domain 2: Study design } \\
\hline \multicolumn{3}{|l|}{ Theoretical framework } \\
\hline 9. Methodological orientation and theory & $\begin{array}{l}\text { What methodological orientation was stated to underpin } \\
\text { the study? eg, grounded theory, discourse analysis, } \\
\text { ethnography, phenomenology, content analysis }\end{array}$ & $\begin{array}{l}\text { Page } 5 \text {, Data analysis, use thematic } \\
\text { analysis }\end{array}$ \\
\hline \multicolumn{3}{|l|}{ Participant selection } \\
\hline 10. Sampling & $\begin{array}{l}\text { How were participants selected? eg, purposive, } \\
\text { convenience, consecutive, snowball }\end{array}$ & Page 4, Participants, purposeful sampling \\
\hline II. Method of approach & $\begin{array}{l}\text { How were participants approached? eg, face-to-face, } \\
\text { telephone, mail, email }\end{array}$ & Page 5, Data collection, face-to-face \\
\hline 12. Sample size & How many participants were in the study? & Page 6, Results, 23 \\
\hline 13. Nonparticipation & $\begin{array}{l}\text { How many people refused to participate or dropped out? } \\
\text { Reasons? }\end{array}$ & $\begin{array}{l}\text { Page 6, two participants, no reasons } \\
\text { provided }\end{array}$ \\
\hline \multicolumn{3}{|l|}{ Setting } \\
\hline 14. Setting of data collection & $\begin{array}{l}\text { Where was the data collected? eg, home, clinic, } \\
\text { workplace }\end{array}$ & $\begin{array}{l}\text { Page } 4 \text {, Setting, a consulting room in } \\
\text { hospital }\end{array}$ \\
\hline 15. Presence of nonparticipants & $\begin{array}{l}\text { Was anyone else present besides the participants and } \\
\text { researchers? }\end{array}$ & $\begin{array}{l}\text { Not reported in paper, no people else } \\
\text { present }\end{array}$ \\
\hline 16. Description of sample & $\begin{array}{l}\text { What are the important characteristics of the sample? eg, } \\
\text { demographic data, date }\end{array}$ & Page 20, Table 2 \\
\hline \multicolumn{3}{|l|}{ Data collection } \\
\hline I7. Interview guide & $\begin{array}{l}\text { Were questions, prompts, guides provided by the } \\
\text { authors? Was it pilot tested? }\end{array}$ & $\begin{array}{l}\text { Page 20, Table I; } \\
\text { Page 5, Data collection, two pilot } \\
\text { interviews }\end{array}$ \\
\hline 18. Repeat interviews & Were repeat interviews carried out? If yes, how many? & $\begin{array}{l}\text { Not reported in paper, no repeat } \\
\text { interviews }\end{array}$ \\
\hline 19. Audio/visual recording & $\begin{array}{l}\text { Did the research use audio or visual recording to collect } \\
\text { the data? }\end{array}$ & Page 5, Data collection, audiotaped \\
\hline 20. Field notes & $\begin{array}{l}\text { Were field notes made during and/or after the interview } \\
\text { or focus group? }\end{array}$ & $\begin{array}{l}\text { Page } 5 \text {, Data collection, memos were } \\
\text { written throughout the data collection } \\
\text { and analysis phases }\end{array}$ \\
\hline
\end{tabular}

(Continued) 
Table SI (Continued)

\begin{tabular}{|c|c|c|}
\hline No item & Guide questions/description & Reported on page number \\
\hline 21. Duration & What was the duration of the interviews or focus group? & Page 5, Data collection, 30-65 minutes \\
\hline 22. Data saturation & Was data saturation discussed? & $\begin{array}{l}\text { Page } 5 \text {, Data collection, data saturation } \\
\text { was achieved }\end{array}$ \\
\hline 23. Transcripts returned & $\begin{array}{l}\text { Were transcripts returned to participants for comment } \\
\text { and/or correction? }\end{array}$ & $\begin{array}{l}\text { Not reported in paper, no transcripts } \\
\text { returned }\end{array}$ \\
\hline \multicolumn{3}{|l|}{ Domain 3: Analysis and findings } \\
\hline \multicolumn{3}{|l|}{ Data analysis } \\
\hline 24. Number of data coders & How many data coders coded the data? & Page 5, Data analysis, three researchers \\
\hline 25. Description of the coding tree & Did authors provide a description of the coding tree? & Not reported in paper \\
\hline 26. Derivation of themes & $\begin{array}{l}\text { Were themes identified in advance or derived from the } \\
\text { data? }\end{array}$ & $\begin{array}{l}\text { Page } 5 \text {, Data analysis, themes were } \\
\text { derived from data }\end{array}$ \\
\hline 27. Software & $\begin{array}{l}\text { What software, if applicable, was used to manage the } \\
\text { data? }\end{array}$ & Page 5, Data analysis, NVivo II \\
\hline 28. Participant checking & Did participants provide feedback on the findings? & Not reported in paper \\
\hline \multicolumn{3}{|l|}{ Reporting } \\
\hline 29. Quotations presented & $\begin{array}{l}\text { Were participant quotations presented to illustrate } \\
\text { the themes/findings? Was each quotation identified? eg, } \\
\text { participant number }\end{array}$ & $\begin{array}{l}\text { Page 6, Results, with identifiers as } \\
\text { "p+number" }\end{array}$ \\
\hline 30. Data and findings consistent & $\begin{array}{l}\text { Was there consistency between the data presented and } \\
\text { the findings? }\end{array}$ & Results, yes \\
\hline 31. Clarity of major themes & Were major themes clearly presented in the findings? & Results, yes \\
\hline 32. Clarity of minor themes & $\begin{array}{l}\text { Is there a description of diverse cases or discussion of } \\
\text { minor themes? }\end{array}$ & Results, yes \\
\hline
\end{tabular}

Abbreviations: COREQ, Consolidated Criteria for Reporting Qualitative Research; MSN, Master of Science in Nursing.

\section{Publish your work in this journal}

Patient Preference and Adherence is an international, peer-reviewed, open access journal that focuses on the growing importance of patient preference and adherence throughout the therapeutic continuum. Patient satisfaction, acceptability, quality of life, compliance, persistence and their role in developing new therapeutic modalities and compounds to optimize clinical outcomes for existing disease states are major areas of interest for the journal. This journal has been accepted for indexing on PubMed Central. The manuscript management system is completely online and includes a very quick and fair peer-review system, which is all easy to use. Visit http://www. dovepress.com/testimonials.php to read real quotes from published authors. 